\title{
Development and Validation of Standardized Pain Management Documentation
}

\author{
Pia LILJAMO ${ }^{\mathrm{a}, 1}$ and Ulla-Mari KINNUNEN ${ }^{\mathrm{b}}$ \\ ${ }^{a}$ Oulu University Hospital, Northern Ostrobothnia District, Oulu, Finland \\ ${ }^{\mathrm{b}}$ University of Eastern Finland, Kuopio, Finland
}

\begin{abstract}
Pain management, assessment and documentation is a crucial part of patient care. However, several studies show flaws in pain management processes. Documentation is not unified or even sufficient. The aim of this study was to describe how patient pain management has been recorded using the nursing diagnoses and nursing interventions of a standardized terminology, the Finnish Care Classification, (FinCC), and how that terminology should be further developed. The research data consisted of the daily nursing documentation notes of patient care episodes $(n=806)$ during inpatient days $(n=2564)$ at several specialty units $(n=9)$. The documentation of pain management was found inadequate and insufficient. The results support the development of a new component, Pain management, and its attendant categories in the new version, FinCC 4.0, to help nurses document pain management in their daily work.
\end{abstract}

Keywords. Documentation, Nursing Informatics, Pain Management, Standardized Nursing Terminology

\section{Introduction}

Effective pain management is of great importance regardless of a patient's illness, severity of the illness, the patient's age, gender or any other circumstance [e.g. 1-3]. Pain management documentation, including information quality and availability, plays a significant role in patient medication safety, patients' and health care professionals' legal protection and the quality control, assessment and development of care [4].

Several studies show that there is room to improve in both the assessment and documentation of pain [5-8]. According to a review, the documentation of pain assessment and management is all too often unsystematic, insufficient or totally lacking. The same applies to the nursing decision-making process, which is left unclear. In addition, the patient's insight into the pain symptoms is not documented. Common agreements or instructions for nurses regarding pain documentation vary greatly [5]. In addition to poor pain documentation, there is a lack of effort to evaluate the effectiveness of pain management interventions. Thus, educational interventions and standardization of pain management and documentation are urgently needed [5,9]. There is evidence that

${ }^{1}$ Corresponding Author, Pia Liljamo, Oulu University Hospital, P.O. Box 1090029 OYS, Oulu, Finland, E-mail: pia.liljamo@ppshp.fi. 
if patient care can be documented structurally using standards and common terminology, that documentation can yield more complete and reliable data that better meet the requirements placed on patient records, including in secondary use $[10,11]$.

In Finland, the national nursing documentation model is based on the nursing process model in decision-making, the essential structured data components (nursing diagnoses, nursing interventions, nursing outcomes, nursing intensity and nursing discharge summary) and the standardized terminology Finnish Care Classification (FinCC). The structure of the FinCC involves a three-level hierarchy featuring three separate classifications: the Classification of Nursing Diagnoses (FiCND), Nursing Interventions (FiCNI) and Nursing Outcomes (FiCNO) [12]. FiCND and FiCNI have the same hierarchical structure, with component, main category and subcategory levels. The component level represents the most abstract level of documentation, while the main category and subcategory levels are more concrete levels of documentation. Nursing outcomes can be evaluated by means of the three qualifiers of FiCNO: 'improved', 'stabilized' and 'deteriorated'. Version 3.0 of the terminology was implemented in 2012. For pain management documentation, a component named Sensory and neurological functions is used in FinCC 3.0 [12,13].

The FinCC expert group begun the terminology update process in 2018. First, evidence was gathered, e.g. national clinical practice guidelines, other scientific evidence and national guidelines, and legislation. Second, the update conducted a survey of end users, i.e. nurses, to receive feedback and development suggestions for the first version of the FinCC 4.0, finally published at the end of 2019 [14].

The aim of this study is to describe how patient pain management has been recorded using the standardized nursing diagnoses and nursing interventions of the FinCC 3.0. The information obtained from this study was utilized when updating the new FinCC 4.0 [14] with a new component, named Pain management, which has received positive feedback from nurses.

\section{Methodology}

The retrospective EHR data, i.e. coded nursing data with free-text in all phases of the nursing process, were collected from one Finnish university hospital representing 36 specialized care inpatient units and 671 beds over a 15-day period in November 2014. The FinCC has been employed in that research hospital since 2007. Certain criteria for inpatient units were set before data were pooled out of the databases: the unit had received a good or excellent quality level of nursing documentation measured by an audit instrument [15]. Research units that passed the selection criteria $(n=9)$ represent a variety of medical specialties: maternity, sensory system and respiratory disease, neurology, traumatology, gastric and plastic surgery, internal medicine and cardiac monitoring. Research data consisted of the daily nursing documentation notes of 806 patient care episodes over 2564 inpatient days, including the morning, evening and night shifts.

For this study, all coded nursing data with free-text related to the patient's pain management were selected from the total research material [12]. Records of pain medication were excluded from the data. To describe the research data, descriptive statistics were used. Qualitative methods were used to analyze the free-text nursing notes. Permission for this study was obtained from the research organization pursuant to the Guidelines of the Finnish Advisory Board on Research Integrity [12,16]. 


\section{Results}

The research data consisting of the different phases of the nursing process included 36 179 coded / structured nursing notes in total. Of all these coded nursing notes 2139 $(5.9 \%)$ were related to pain management (Table 1). In the first phase of the nursing process, Care planning/determining need for care, 278 (7.4\%) FiCND nursing diagnoses related to pain management were employed. The most frequently encountered nursing diagnoses were 'Chest pain' $(27.3 \%)$, 'Acute pain' $(23.0 \%)$ and 'Pain related to an intervention (e.g. surgical operation)’ (20.5\%).

Table 1. Main and subcategories of FiCND 3.0 and FiCNI 3.0 related to pain management used in the different phases of nursing process

\begin{tabular}{|c|c|c|c|}
\hline $\begin{array}{l}\text { Phase of nursing } \\
\text { process }\end{array}$ & FiCND 3.0 and FiCNI 3.0 categories & $\begin{array}{l}\text { Number of } \\
\text { categories } \\
\text { related to pain } \\
\text { management } \\
n(\%)\end{array}$ & $\begin{array}{c}\text { Number of all } \\
\text { FiCND and } \\
\text { FICNI } 3.0 \\
\text { categories in the } \\
\text { whole data } \\
\text { n }(\%)\end{array}$ \\
\hline \multirow{13}{*}{$\begin{array}{l}\text { Care planning / } \\
\text { Determining need } \\
\text { for care }\end{array}$} & FiCND 3.0 nursing diagnoses & $278(7.4)$ & $3754(10.4)$ \\
\hline & Chest pain (sc) & $76(27.3)$ & \\
\hline & Acute pain $(\mathrm{mc})$ & $64(23.0)$ & \\
\hline & Pain related to an intervention (sc) & $57(20.5)$ & \\
\hline & Persistent pain $(\mathrm{mc})$ & $37(13.3)$ & \\
\hline & Traumatic pain (sc) & $24(8.6)$ & \\
\hline & Inflammatory pain (sc) & $12(4.3)$ & \\
\hline & Headache (sc) & $5(1.8)$ & \\
\hline & Pain related to tissue damage (sc) & $2(0.7)$ & \\
\hline & Neuropathic pain (sc) & $1(0.4)$ & \\
\hline & Idiopathic pain (sc) & $0(0.0)$ & \\
\hline & Cancer pain (sc) & $0(0.0)$ & \\
\hline & $\begin{array}{l}\text { Need for information related to pain } \\
(\mathrm{mc})\end{array}$ & $0(0.0)$ & \\
\hline $\begin{array}{l}\text { Care planning / } \\
\text { Setting goals of care }\end{array}$ & Sensory and neurological functions (c) & $187(6.5)$ & $2867(7.9)$ \\
\hline \multirow[t]{5}{*}{$\begin{array}{l}\text { Implementation of } \\
\text { interventions }\end{array}$} & $\begin{array}{l}\text { FiCNI 3.0 nursing interventions } \\
\text { Monitoring of the pain }(\mathrm{mc})\end{array}$ & $\begin{array}{l}\mathbf{1 5 4 5 ( 5 . 6 )} \\
1470(95.1)\end{array}$ & $27566(76.2)$ \\
\hline & Assessment of the pain (sc) & $38(2.5)$ & \\
\hline & Pain management (mc) & $35(2.3)$ & \\
\hline & Assessment of the intensity of pain (sc) & $2(0.1)$ & \\
\hline & Guidance of the pain management $(\mathrm{mc})$ & $0(0.0)$ & \\
\hline $\begin{array}{l}\text { Evaluation of } \\
\text { nursing outcomes }\end{array}$ & Sensory and neurological functions (c) & $129(6.5)$ & $1992(5.5)$ \\
\hline $\begin{array}{l}\text { All phases of the } \\
\text { nursing process }\end{array}$ & Total & $2139(5.9)$ & $36179(100)$ \\
\hline
\end{tabular}

$*$ component $=\mathrm{c} ;$ main category $=\mathrm{mc} ;$ subcategory $=\mathrm{sc}$

Overall nurses made the most of coded nursing notes in the phase Implementation of nursing interventions (76.2\%). Pain-related nursing interventions comprised $5.6 \%$ of the notes. The most-used nursing intervention related to the patient's pain management 
was 'Monitoring the pain' (95.1\%). Free-text annotations associated with 'Monitoring the pain' were related to the intensity and location of the pain. Pain intensity expressions included pain is under control $(\mathrm{n}=309)$, patient is pain-free or has no pain $(\mathrm{n}=288)$ or patient has headache or headache is relieved $(\mathrm{n}=29)$. Pain intensity, as documented by the numerical rating scale (NRS), was used 17 times.

\section{Discussion}

Pain management, assessment and documentation is unsatisfactory [5-8], which hinders good quality care, patient care coordination and patient safety [4], and, as importantly, may result in unnecessary suffering and an unpleasant patient experience. The results show that patient pain management and assessment have been documented in a variable and generalized manner. At the Care planning / Determining need for care phase, only three categories of the FiCND 3.0 were used in a majority of cases. At the Implementation of interventions phase, one FiNCI 3.0 nursing intervention, 'Monitoring of the pain', was used in $95 \%$ of the cases. There was no indication in the nursing records that patient had been given guidance with pain management. These results are consistent with previous research, showing that patient education is inadequately documented, and nurses may not see the importance of documenting it $[5,12]$. In addition, the frequent use of free-text for documentation in lieu of the FinCC components and main and sub categories gives rise to terminology which is incompatible with good quality documentation [10,11].

Managing pain is one of the most important aspects of patient care [2,5]. In the FinCC 3.0, five categories permit the recording of pain management related nursing interventions [12]. Based on the results of this study and the feedback received from the nurses, the FinCC expert group is substantially vindicated in their decision to improve the terminology to better support the recording of pain management, and to include a new component 'Pain management' in FinCC 4.0 [14]. In the Pain management component of FiCND 4.0, there are 15 nursing diagnoses, with eight main categories with 23 concrete subcategories of nursing interventions in FiCNI. One new main category is 'Non-pharmacological management of pain' with 11 interventions like 'Postural therapy' and 'Mental imagery'. There is also a category for 'Assessment of the effects of non-pharmacological management of pain', as well as 'Assessment of the intensity of pain at rest', and 'Assessment of the intensity of pain when mobile' [14]. The goal for these new terms in the revised terminology is to remedy nurses' skills deficit to record more than just 'painkillers given', and more completely document the content of the care provided to patients [2,9], as well as facilitate better quality data within nursing records $[10,11]$. The documentation of medication, prescribed by the physician and administered by the nurse, is an essential part of pain management and its documentation. In this study, medication management was excluded. In the FinCC, the component 'Medication' is used for medication management and it bears consideration that pain management could also have been recorded using that component. 


\section{Conclusion}

Patient care must be evidence-based. In addition, the standardized terminology must derive from scientific evidence. Thus, daily patient care will be documented in a unified manner, and it will become more distinctly visible and transparent. This supports patient care quality and continuity, patient safety, and protects health care professionals from legal liability. 'Pain management'-component will support the documentation of e.g. acute or chronic pain, or a newborn or elderly patient's. Further, the FinCC 4.0 requires the validation of all its components to support the documentation needs. There is also interest of cross mapping the FinCC with the SNOMED CT in order to benefit from the use of different terminologies and to allow international health care data comparisons and benchmarking.

\section{References}

[1] Fillingim RB, Loeser JD, Baron R, Edward RR. Assessment of Chronic Pain: Domains, Methods, and Mechanisms. J Pain. 2016 September; 17(9 Suppl): T10-T20. doi:10.1016/j.jpain.2015.08.010.

[2] Alotaibi K, Higgins I, Day J, Chan S. Paediatric pain management: knowledge, attitudes, barriers and facilitators among nurses - integrative review. Int Nurs Rev. 2018; 65: 524-533.

[3] Minaya-Freire A, Ramon-Aribau A, Pou-Pujol G, Fajula-Bonet M, Subirana-Casacuberta M. Facilitators, Barriers, and Solutions in Pain Management for Older Adults with Dementia. Pain Manag Nurs. Available online 29 May 2020 (In Press) Available: https://doi.org/10.1016/j.pmn.2020.03.003

[4] WHO, Medication Safety in Transitions of Care, Geneva, World Health Organization, 2019 (WHO/UHC/SDS/2019.9). Licence: CC $\quad$ BY-NC-SA $3.0 \quad$ IGO. Available: https://apps.who.int/iris/bitstream/handle/10665/325453/WHO-UHC-SDS-2019.9-eng.pdf?ua=1

[5] Heikkilä K, Peltonen L-M, Salanterä S. Postoperative pain documentation in a hospital setting: a topical review. Scand J Pain. 2016; 11;77-89.

[6] Heikkilä K, Axelin A, Peltonen L-M, et al. Pain process of patients with cardiac surgery-Semantic annotation of electronic patient record data. J Clin Nurs. 2019; 28:1555-1567.

[7] Ardon A, Warrick M, Wickas T. A Multi-faceted Educational Approach for Pain Metric Recording Prior to Knee and Hip Arthroplasty: Effects on Documentation by an Acute Pain Service. Cureus. 2019; 11(6): e5030. DOI 10.7759/cureus.5030

[8] Chineke I, Adams Curry M, Bell W, Flood D, Mishra P, Power S, Bernal-Mizrachi L. Improving Documentation of Pain and Constipation Management Within the Cancer Center of a Large Urban Academic Hospital. J Oncol Pract. 2020; 16 (3): e251- e256.

[9] Shoqirat N, Mahasneh D, Dardas L, Singh C, Khresheh R. Nursing Documentation of Postoperative Pain Management, A Documentary Analysis. J Nurs Care Qual. 2019; 34: 279-284.

[10] Saranto K, Kinnunen U-M, Kivekäs E, Lappalainen AM, Liljamo P, Rajalahti E, Hyppönen H. Impacts of structuring nursing records: a systematic review. Scand J Caring Sci. 2014; Dec; 28(4):629-47. doi: 10.1111/scs.12094. Epub 2013 Nov 18. Review.

[11] Macieira TGR, Chianca TCM, Smith MB, Yao Y, Bian J, Wilkie DJ, Lopez KD, Keenan GM. Secondary use of standardized nursing care data for advancing nursing science and practice: a systematic review. J Am Med Inform Assoc. 2019; 26(11): 1401-1411.

[12] Liljamo P, Kinnunen U-M, Saranto K. Assessing the relation of the coded nursing care and nursing intensity data: Towards the exploitation of clinical data for administrative use and the design of nursing workload. Health Informatics J. 2020; 26(1): 114-128. https://doi.org/10.1177/1460458218813613

[13] Kinnunen U-M, Junttila K, Liljamo P et al. FinCC and the national documentation model in EHR - user feedback and development suggestions, Stud Health Technol Inform 2014; 201: 196-202.

[14] Kinnunen U-M, Liljamo P, Härkönen M, Ukkola T, Kuusisto A, Hassinen T, Moilanen K. User Guide, The Finnish Care Classification System, 4.0, Finnish Institute for Health and Welfare, Helsinki, 2019.

[15] Mykkänen M, Saranto K, Miettinen M. Nursing audit as a method for developing nursing care and ensuring patient safety. Nurs Inform 2012; 2012: 301.

[16] Finnish National Board on Research Integrity TENK. The ethical principles of research with human participants and ethical review in the human sciences in Finland. Finnish National Board on Research $\begin{array}{llll}\text { Integrity } & \text { TENK } & \text { guidelines } & 2019 .\end{array}$ https://www.tenk.fi/sites/tenk.fi/files/Ihmistieteiden_eettisen_ennakkoarvioinnin_ohje_2019.pdf 